\title{
Autoimmune regulator-overexpressing dendritic cells induce $T$ helper 1 and $T$ helper 17 cells by upregulating cytokine expression
}

\author{
HAIJUN LI*, DONGBEI LI*, JITONG SUN, YINAN LI, WEI YANG and YI LI \\ Department of Immunology, Norman Bethune College of Medicine, Jilin University, Changchun, Jilin 130021, P.R. China
}

Received February 1, 2015; Accepted October 6, 2015

DOI: $10.3892 / \mathrm{mmr} .2015 .4530$

\begin{abstract}
The autoimmune regulator (Aire) protein is a transcriptional activator that is essential in central immune tolerance, as it regulates the ectopic expression of many tissue-restricted antigens in medullary thymic epithelial cells. Aire expression has also been described in hematopoietic cells, such as monocytes/macrophages and dendritic cells (DCs), in the peripheral immune system. However, the role of Aire expression in peripheral immune system cells, including DCs, remains to be elucidated. In the present study, the effects of secreted cytokines from Aire-overexpressing DCs on cluster of differentiation (CD) $4^{+} \mathrm{T}$ cell subsets were investigated. The dendritic cell line, DC2.4, which overexpresses Aire, was co-cultured with CD $4^{+}$T cells from splenocytes using Transwell inserts. The results indicate that Aire-overexpressing cells induce T helper (Th)1 subsets by increasing interleukin (IL)-12 expression, and induce Th17 subsets by upregulating IL-6 and transforming growth factor (TGF)- $\beta$ production. In addition, it was observed that increased levels of phosphorylated extracellular signal-regulated kinases and p38 upregulated the expression of cytokines in Aire-overexpressing cells. These data suggest that Aire may have a role in inducing Th1 and Th17 differentiation by upregulating cytokine expression in DCs.
\end{abstract}

\section{Introduction}

The autoimmune regulator (Aire) protein is a transcription factor that is highly expressed in medullary thymic epithelial

Correspondence to: Professor Wei Yang or Professor $\mathrm{Yi} \mathrm{Li}$, Department of Immunology, Norman Bethune College of Medicine, Jilin University, 126 Xinmin Avenue, Changchun, Jilin 130021, P.R. China

E-mail: ywei@jlu.edu.cn

E-mail: liyi@jlu.edu.cn

*Contributed equally

Key words: autoimmune regulator, dendritic cells, cytokines, cluster of differentiation $4^{+} \mathrm{T}$ cell subsets cells (mTECs) (1). Aire is important in deleting autoreactive $\mathrm{T}$ cells and inducing regulatory $\mathrm{T}$ cells (Tregs). It maintains central immune tolerance, preventing autoimmunity by regulating tissue restrictive antigen (TRA) expression in mTECs of the thymus (2-5). The mutation or deletion of the Aire gene in humans results in autoimmune polyendocrine syndrome type I (APS-1) (6), which is primarily characterized by multiple organ disorders that are mediated by an autoimmune response. This disorder is also termed autoimmune polyendocrinopathy-candidiasis-ectodermal dystrophy (APECED). Patients exhibiting APECED may also develop other disorders, including Addison's disease, hypoparathyroidism and diabetes. In addition, APECED patients are susceptible to developing Candida albicans infections due to immunodeficiency $(7,8)$.

Although primarily expressed in the thymus, Aire is also detected in dendritic cells (DCs), macrophages and stromal cells of peripheral tissues, particularly in the blood and the lymph nodes $(1,9,10)$. However, the role of Aire at these sites remains to be elucidated. In addition, the reason for the susceptibility of APECED patients to C. albicans infection requires further investigation. Previous studies identified that Aire regulates certain TRAs in peripheral tissues to maintain peripheral tolerance by deleting autoreactive $\mathrm{T}$ cells, complementary to the action at the thymus $(11,12)$. Furthermore, alterations in the antigen-presenting capabilities of DCs and macrophages have been described in Aire-knockout (KO) mice (13), suggesting that Aire regulates the immune response. However, other underlying mechanisms by which Aire regulates tolerance or the immune response in cells of peripheral tissues cannot be excluded.

Cluster of differentiation (CD) $4^{+} \mathrm{T}$ helper cells are crucial in regulating the immune response and in maintaining peripheral tolerance $(14,15)$. Naive $\mathrm{CD}^{+} \mathrm{T}$ cells may differentiate into distinct subsets, including $\mathrm{T}$ helper (Th)1, Th2, Th17, and Tregs, as well as Th9 and Th22 (16-19), subsequent to co-stimulation with and cytokine signals from DCs. These signals contribute significantly to the development of $\mathrm{CD}^{+}$ $\mathrm{T}$ cell subsets. Therefore, the present study hypothesized that Aire expression in DCs is involved in the immune response and in peripheral tolerance by affecting $\mathrm{CD} 4^{+} \mathrm{T}$ cell subsets.

In the current study, the effects of cytokines secreted by the dendritic cell line, DC2.4, which overexpresses Aire, on the differentiation of $\mathrm{CD}^{+} \mathrm{T}$ cell subsets were investigated. The results demonstrate that Aire-overexpressing cells induce Th1 
and Th17 differentiation by upregulating interleukin (IL)-12, IL-6 and transforming growth factor (TGF)- $\beta$. Further analysis indicated that increased phosphorylation of extracellular signal-regulated kinases (ERK) and p38 may upregulate the expression of these cytokines in Aire-overexpressing cells.

\section{Materials and methods}

Cells and animals. The DC2.4 cell line was obtained from the Shanghai Cell Research Institute (Shanghai, China) and cultured in 10\% newborn calf serum (Hyclone; GE Healthcare Life Sciences, Logan, UT, USA) in RPMI-1640 (Gibco-BRL; Thermo Fisher Scientific, Inc.,Waltham, MA, USA). The DC2.4 cells were transfected with pEGFPC1/Aire or pEGFPC1 plasmids (Takara Bio, Inc., Otsu, Japan), and stable cell lines were obtained using G418 selection agents (Sigma-Aldrich, St. Louis, MO, USA), as previously described (20). A total of 60 male C57BL/J6 mice (4-5 weeks-old; 18-20 g) were purchased from the Experimental Animal Center of Jilin University (Changchun, China), and all mice were housed under specific pathogen-free conditions at room temperature under a $12 \mathrm{~h}$ light/dark cycle, and fed with mouse nutritional food. The present study was approved by the Institutional Animal Care and Use Committee of Jilin University, and all mice were treated in accordance with the Guide for the Care and Use of Laboratory Animals.

Non-contact co-culture of the DC2.4 cell lines with $C D 4^{+}$ $T$ cells. The mice were sacrificed by cervical dislocation, then the spleens were removed from the C57BL/J6 mice and gently dissociated into single-cell suspensions using an aseptic syringe filled with $0.1 \mathrm{~mol} / 1$ ( $\mathrm{pH} 7.4)$ phosphate-buffered saline (PBS). $\mathrm{CD}^{+} \mathrm{T}$ cells were purified from the spleen cell suspension using a Mouse CD4 ${ }^{+}$T Lymphocyte Enrichment set (BD Biosciences, Franklin Lakes, NJ, USA) according to the manufacturer's protocols. Transwell ${ }^{\circledR}$ Permeable Supports (3- $\mu \mathrm{m}$ pores, plasma-treated polycarbonate inserts; Corning Life Sciences, Corning, NY, USA) were utilized for the paracrine, non-contact cell co-cultures. Aire-overexpressing cells (Aire cells) or empty vector (control cells) were seeded in 6 -well plates at $2 \times 10^{5}$ per well in $2 \mathrm{ml}$ media. Once the cells had attached to the wells, CD4 ${ }^{+} \mathrm{T}$ cells $\left(4 \times 10^{6}\right.$ per well) were added to the top of the Transwell chamber, and incubated for $48 \mathrm{~h}$ at $37^{\circ} \mathrm{C}$. Finally, the $\mathrm{CD} 4^{+} \mathrm{T}$ cells were harvested for flow cytometry and reverse transcription-quantitative polymerase chain reaction (RT-qPCR) analyses.

$R N A$ isolation and RT-qPCR. Total RNA was extracted from the harvested $\mathrm{CD} 4^{+} \mathrm{T}$ cells (as described above) or from the Aire and control DC2.4 cells using RNAiso ${ }^{\mathrm{TM}}$ PLUS (Takara Bio, Inc.), and dissolved in diethylpyrocarbonate-treated water (Takara Bio, Inc.). The quantity of total RNA was then measured using an Epoch multi-volume spectrophotometer system (BioTeke Corporation, Beijing, China). cDNA was synthesized from $1.0 \mathrm{mg}$ total RNA using reverse transcriptase (Takara Bio, Inc.), Moloney murine leukemia virus (Takara Bio, Inc.) and oligonucleotides (dT; Takara Bio, Inc.) in a total volume of $20 \mathrm{ml}$, according to the manufacturer's protocols (Takara Bio, Inc.). RT-qPCR was performed using an ABI PRISM 7300 sequence detection system (Applied Biosystems; Thermo Fisher Scientific, Inc.) with SYBR Premix Ex Taq ${ }^{\mathrm{TM}}$ II
(Takara Bio, Inc.) following the manufacturer's protocol and using the following conditions: $95^{\circ} \mathrm{C}$ for $30 \mathrm{sec}, 95^{\circ} \mathrm{C}$ for $5 \mathrm{sec}$, and $60^{\circ} \mathrm{C}$ for $30 \mathrm{sec}$ for 40 cycles. The results were analyzed according to the $2^{-\Delta \Delta \mathrm{Cq}}$ formula. The following primers (Takara Bio, Inc.) were used: Sense, 5'-GACTTCAACAGCAACTCC CACTC-3' and antisense, 5'-TAGCCGTATTCATTGTCATAC CAG-3' for GAPDH; sense, 5'-CCCATCCCTTCCCTGTAT-3' and antisense, 5'-GTCCATTCTCCGTTCTCCA-3' for T-box transcription factor 21 (T-bet); sense, 5'-TCCAGTCCTCAT CTCTTCAC -3' and antisense, 5'-GTCTCCAGCTTCATG CTATC-3' for GATA-binding protein 3 (Gata3); sense, 5'-CCC CTGGAGGTGTCTGATGG-3' and antisense, 5'-TGTGCT TGGACGAGAACTGGA-3' for Spi-1 proto-oncogene (PU.1); sense, 5'-AGATTCCAGGTGACTCTGTG-3' and antisense, 5'-CTGCCCTGTCAGAGTATTTC-3' for interferon regulatory factor 4 (IRF4); sense, 5'-CCGCTGAGAGGGCTTCAC-3' and antisense 5'-TGCAGGAGTAGGCCACATTACA-3' for RAR-related orphan receptor $\gamma$ isoform two $(\mathrm{ROR} \gamma \mathrm{t})$; sense, 5'-GCTACTCCACTTCAGCCACC-3' and antisense, 5'-ACT GTCATGCCACTTTCTCC-3' for aryl hydrocarbon receptor (AHR); sense, 5'-TACTCGCATGTTCGCCTCTTCA-3' and antisense, 5'-ATTCATCTACGGTCCACACTGCT-3' for forkhead box P3 (FoxP3); sense, 5'-ACTTGAACTACGCTA CGAGAG-3' and antisense, 5'-CTTGACTCCGCCTCATCC GGTA-3' for interleukin-12 subunit $\beta$; sense, 5'-GAAACCGCT ATGAAGTTCCTCTCTG-3' and antisense, 5'-GTATCCTCT GTGAAGTCTCCTCTCC-3' for IL-6; and sense, 5'-GCCCTG GATACCAACTATTGC-3' and antisense, 5'-GCAGGAGCG CACAATCATGTT-3' for TGF- $\beta$.

Flow cytometry. The cells were collected and counted, and $1 \times 10^{6}$ cells were suspended in PBS (100 $\mu 1$ total volume). To compare the different cell subsets, $\mathrm{CD} 4^{+} \mathrm{T}$ cells were first incubated with rat anti-mouse $\mathrm{CD}^{+} \mathrm{PE}$-cyanine 7 (cat. no. 25-0041; 1:160; eBioscience, Inc., San Diego, CA, USA) on ice for $45 \mathrm{~min}$ and subsequently fixed with Fixation/Permeabilization Concentrate and Diluent (eBioscience, Inc.) for $1 \mathrm{~h}$. The cells were treated with $0.1 \%$ saponin (Sigma-Aldrich) and rat anti-mouse IL-4-fluorescein isothiocyanate (cat. no. M100I9-02; 1:200; Tianjin Sungene Biotech, Co., Ltd., Tianjin, China), rat anti-mouse IFN- $\gamma$ PE (cat. no. 12-7311; 1:160; eBioscience, Inc.), rat anti-mouse IL-17A-PE (cat. no. 12-7177; 1:160; eBioscience, Inc.), rat anti-mouse FoxP3-Alexa Fluor 647 (cat. no. 50-5773; 1:100; eBioscience, Inc.) or rat anti-mouse IL-9-PE (cat. no. 516404; 1:100; Biolegend, Inc., San Diego, CA, USA) antibodies at $4^{\circ} \mathrm{C}$ for $1 \mathrm{~h}$. The cells were washed twice with PBS and resuspended in $2 \%$ paraformaldehyde (Sigma-Aldrich) for analysis using a BD FACSCalibur ${ }^{\mathrm{TM}}$ flow cytometer (BD Biosciences, Franklin Lakes, NJ, USA). For phosphorylated (p)-ERK staining, Aire and control DC2.4 cells were collected and counted using a cell count board. The fixed cells were stained with anti-mouse p-ERK (T202/Y204; cat. no. 14-9109; 1:100) and rabbit anti-mouse p-p38 (T180; cat. no. YP0338; 1:100; ImmunoWay Biotechnology, Co., Newark, DE, USA) antibodies, followed by staining with a secondary goat anti-mouse antibody (BD Biosciences).

Cytokine secretion assays. IL-6, IL-12 and TGF- $\beta$ expression levels in the cell-free supernatants of the control or 


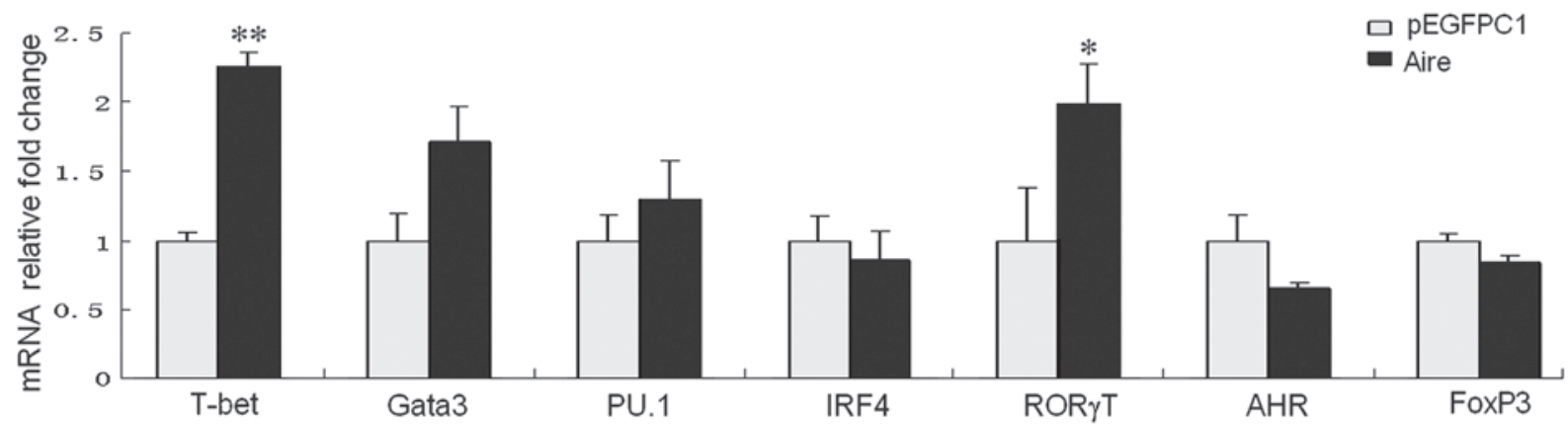

Figure 1. Expression levels of the master regulators in $\mathrm{CD}^{+}{ }^{+} \mathrm{T}$ cells, purified from spleen cells co-cultured with Aire-overexpressing or control cells submitted to Transwell assays for $48 \mathrm{~h}$. The mRNA levels were determined using quantitative reverse transcription-polymerase chain reaction. All data are shown as the expression levels relative to the expression of GAPDH and are depicted as the fold change relative to control cells, normalized to 1 . The data are expressed as means \pm standard deviation from between three and five independent experiments. ${ }^{*} \mathrm{P}<0.05,{ }^{* *} \mathrm{P}<0.01 \mathrm{vs}$. pEGFPC1. T-bet, T-box transcription factor 21 ; Gata3, GATA-binding protein 3; PU.1, Spi-1 proto-oncogene; IRF4, interferon regulatory factor 4; ROR $\gamma$ T, RAR-related orphan receptor gamma isoform 2; AHR, aryl hydrocarbon receptor; FoxP3, forkhead box P3; CD, cluster of differentiation; Aire, autoimmune regulator; mRNA, messenger RNA.

A

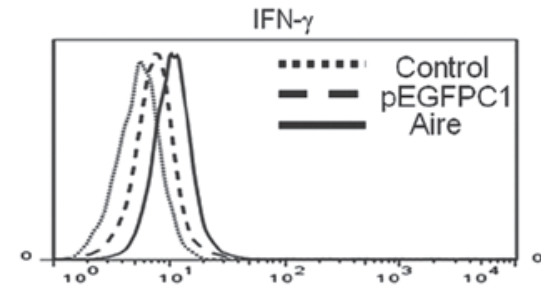

IL-4
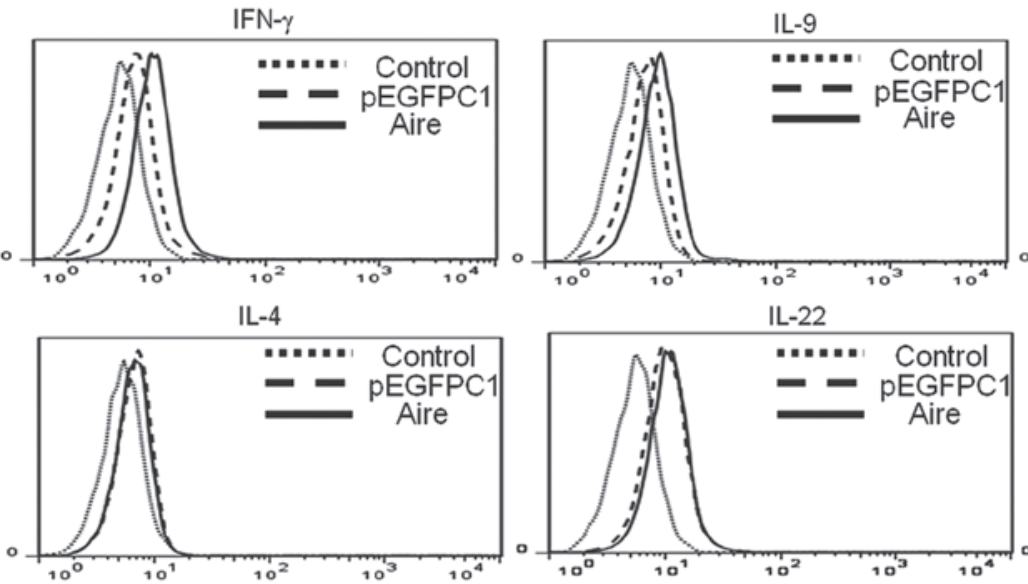

IL-22
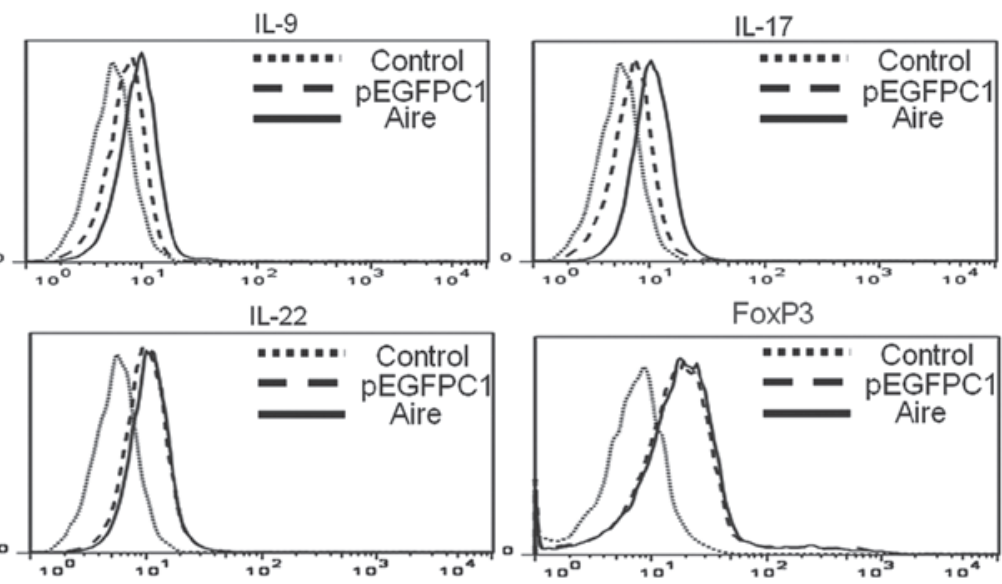

FoxP3

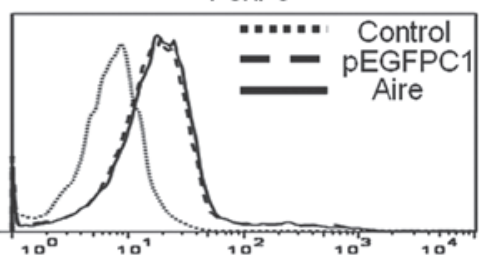

B

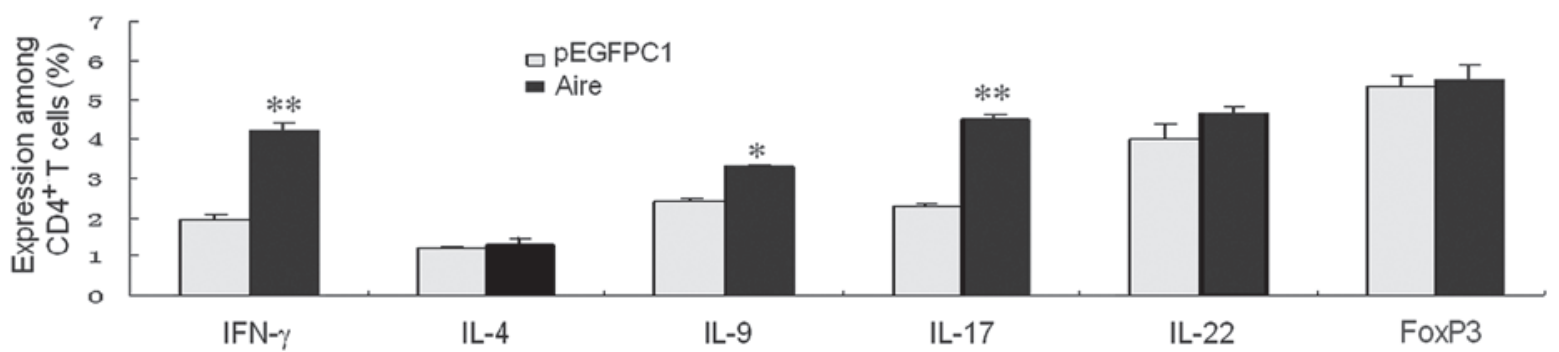

Figure 2. Supernatant of Aire cells affects the number of $\mathrm{CD}^{+} \mathrm{T}$ cells and their subsets. CD4+ $\mathrm{T}$ cells were purified from spleen cells and co-cultured with Aire or control cells, and submitted to Transwell assays for 48 h. (A) The percentages of Tregs and Th1, Th2, Th9, Th17, and Th22 cells among the CD4 ${ }^{+} \mathrm{T}$ cells were analyzed by fluorescence-activated cell sorting. (B) The emitted fluorescence was analyzed using FlowJo 7.6 software. The results from a minimum of three experiments are presented as the percentage of positive cells \pm standard deviation. ${ }^{*} \mathrm{P}<0.05,{ }^{* *} \mathrm{P}<0.05$ vs. pEGFPC1. CD, cluster of differentiation; Th, T helper; IL, interleukin; IFN- $\gamma$, interferon $\gamma$; FoxP3, forkhead box P3; Aire, autoimmune regulator.

Aire-overexpressing DC2.4 cell cultures $\left(1 \times 10^{6}\right.$ cells/6-well plate in $2 \mathrm{ml}$ for $48 \mathrm{~h}$ ) were measured using an ELISA kits (eBioscience, Inc.) according to the manufacturer's protocol.

Antibody blocking. The cytokines secreted from the Aire or control cells into the supernatants were neutralized with anti-mouse TGF- $\beta$ (cat. no. MAB1835; $1: 100$; R\&D Systems, Inc., Minneapolis, MN, USA), rat anti-mouse IL-6 (cat. no. M100I5-14; 1:20; BioLegend, Inc.), and rat anti-mouse IL-12 (cat. no. M100I121-14; 1:20; Tianjin Sungene Biotech) antibodies for $2 \mathrm{~h}$. Freshly isolated $\mathrm{CD}^{+}{ }^{+} \mathrm{T}$ cells were added to the Transwell chamber culture and incubated for $48 \mathrm{~h}$ at $37^{\circ} \mathrm{C}$, following which the $\mathrm{CD} 4^{+} \mathrm{T}$ cells were harvested for fluorescence-activated cell sorting (FACS) analysis.

Statistical analysis. All experimental data are reported as means \pm experimental standard errors. Statistical analysis was performed using Student's t-test and $\mathrm{P}<0.05$ was considered to indicate a statistically significant difference.

\section{Results}

Aire-overexpressing DC2.4 cells induce Th1 and Th17 subsets. The stimulatory signals from DCs influence CD $4^{+}$ 
A

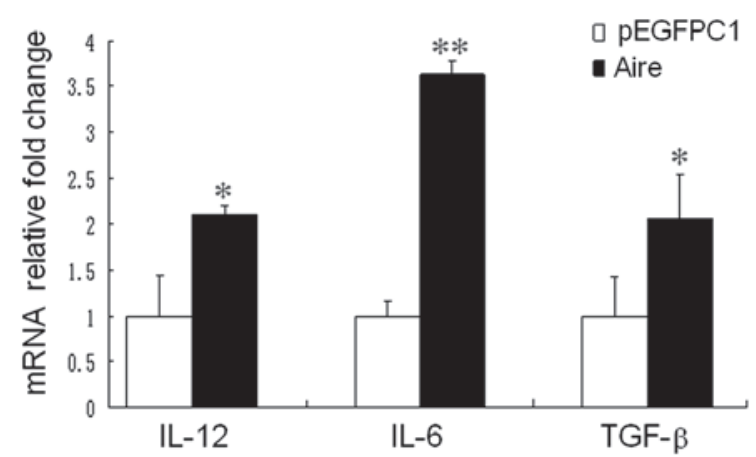

B

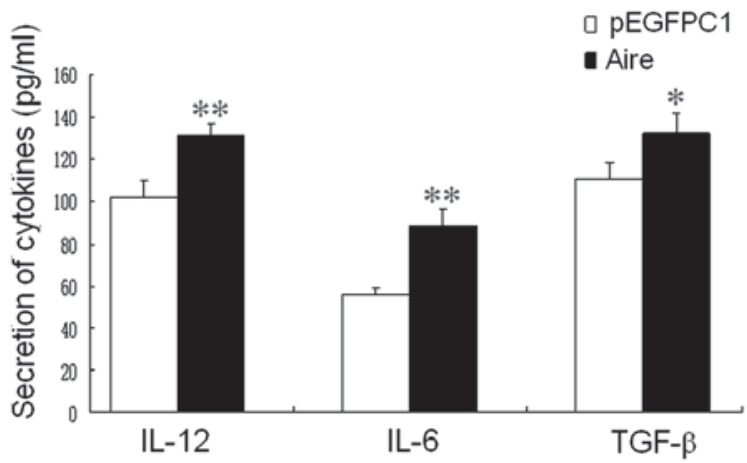

Figure 3. (A) Aire affects the expression levels of IL-12, IL-6 and TGF- $\beta$ in DC 2.4 cells and the mRNA levels of IL-12, IL-6 and TGF- $\beta$ in DC2.4 cells transfected with either pEGFPC1/Aire or pEGFPC1 plasmids, as detected by quantitative reverse transcription-polymerase chain reaction. (B) $\mathrm{CD} 4^{+} \mathrm{T}$ cells purified from spleen cells were co-cultured with Aire or control cells and submitted to Transwell assays for $48 \mathrm{~h}$, the supernatants were collected, and IL- 12 , IL- 6 and TGF- $\beta$ were detected. The data are expressed as means \pm standard deviation of between three and five independent experiments. ${ }^{*} \mathrm{P}<0.05,{ }^{* *} \mathrm{P}<0.01 \mathrm{vs}$. pEGFPC1. IL, interleukin; TGF- $\beta$, transforming growth factor $\beta$; Aire, autoimmune regulator; mRNA, messenger RNA; CD, cluster of differentiation.

A
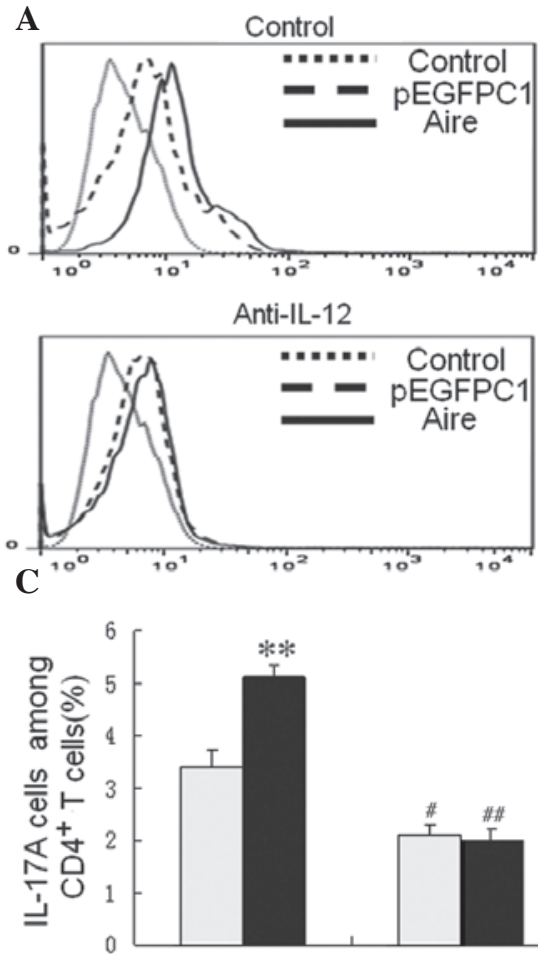

Anti-IL-6

Anti-TGF- $\beta$
B
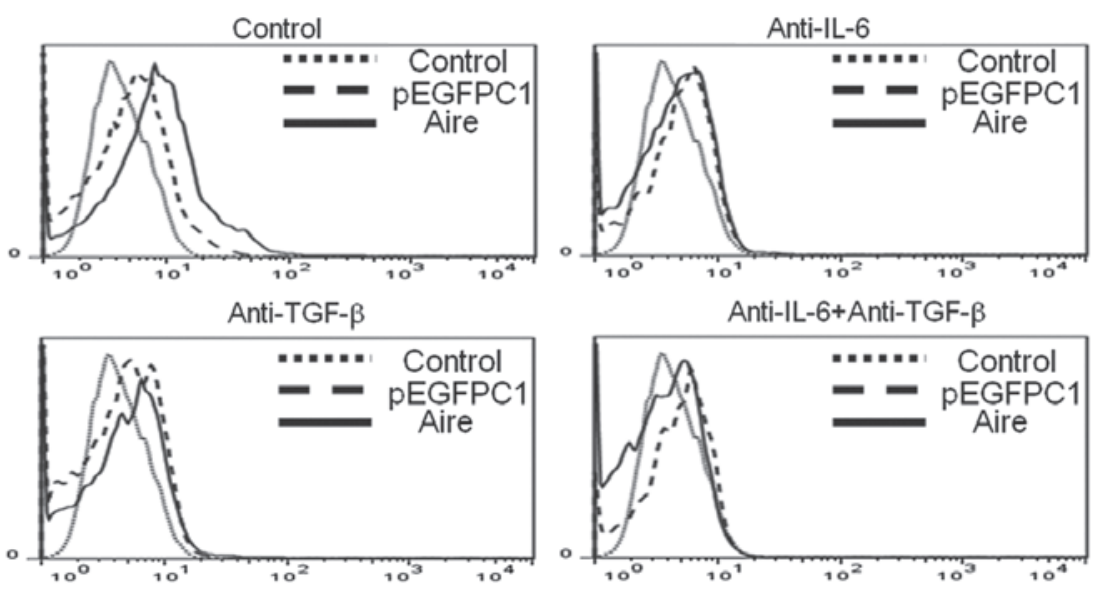

pEGFPC1

- Aire

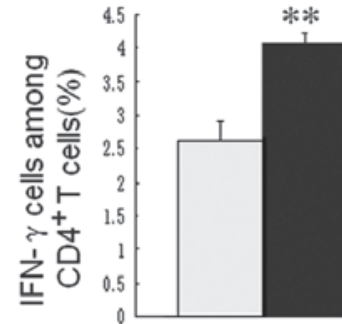

Control
pEGFPC1

- Aire

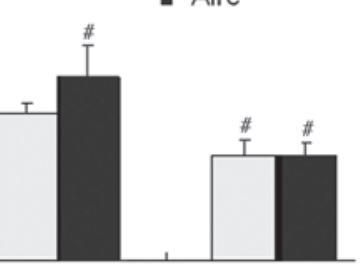

Figure 4. (A) IFN- $\gamma$ expression levels in $\mathrm{CD}^{+} \mathrm{T}$ cells were examined by FACS following 48-h co-culture with Aire or control cells that were either untreated or preblocked with anti-IL-12 antibody. (B) The IL-17A expression levels in CD4 ${ }^{+} \mathrm{T}$ cells were examined by FACS after a 48-h co-culture with Aire or control cells that were untreated or preblocked with anti-IL- 6 and anti-TGF- $\beta$ antibodies, either separately or in combination. (C) The results are presented as the percentage of positive cells \pm standard deviation. Each experiment was repeated at least three times, and each group was compared with the pEGFPC1 group. ${ }^{* *} \mathrm{P}<0.01$, compared with the pEGFPC1 group; ${ }^{\#} \mathrm{P}<0.05,{ }^{\# \#} \mathrm{P}<0.01$, Aire or pEGFPC1 groups with antibody blocking compared with Aire or pEGFPC1 groups with no antibody blocking. IL, interleukin; TGF- $\beta$, transforming growth factor $\beta$; CD, cluster of differentiation; IFN- $\gamma$, interferon- $\gamma$; FACS, fluorescence-activated cell sorting; Aire, autoimmune regulator.

T cell subsets by regulating the expression levels of transcription factors. These different $\mathrm{CD} 4^{+} \mathrm{T}$ cell subsets perform their functions by secreting various cytokines, thus, identification can be conducted by analysis of expression profiles of these master regulators and cytokines. The transcription factors unique to the CD4 ${ }^{+}$T cell subsets, Th1, Th2, Th9, Th17, Th22, and Tregs are T-bet, Gata3, PU.1 and IRF4, ROR $\gamma$ T, AHR, and FoxP3, respectively. Additionally, the unique cytokines for Th1, Th2, Th9, Th17, and Th22 cells are interferon (IFN)- $\gamma$, IL-4, IL-9, IL-17A and IL-22, respectively (16-19,21).

To examine the effects of Aire cells on the $\mathrm{CD}^{+}{ }^{+} \mathrm{T}$ cell subsets, the messenger (m)RNA expression levels of the master regulators were detected by RT-qPCR. All the master regulators were expressed in $\mathrm{CD}^{+} \mathrm{T}$ cells; however, compared with the control, T-bet (the marker of Th1 cells) and ROR $\gamma \mathrm{T}$ (the marker of Th17 cells) were significantly upregulated in 
A

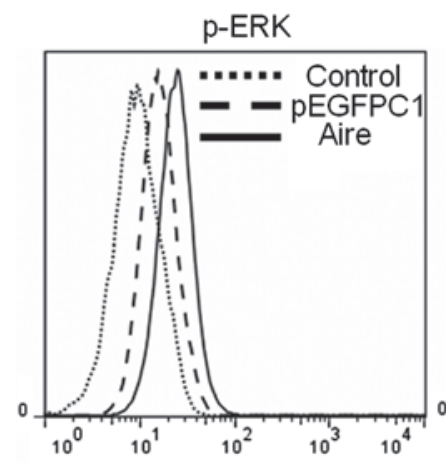

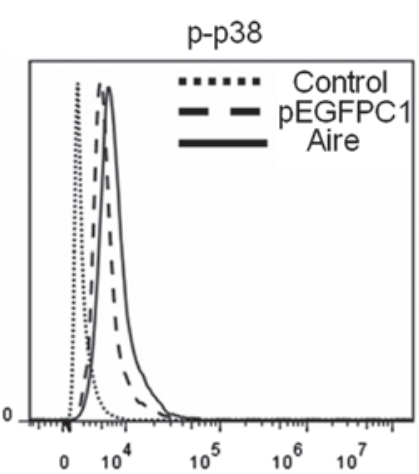

B

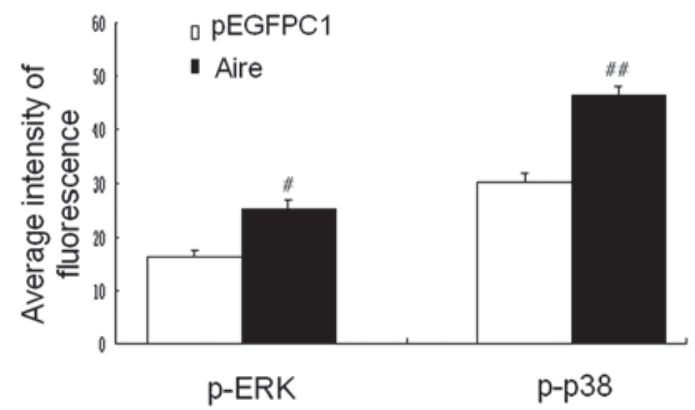

Figure 5. (A) Phosphorylation levels of - and p38 in Aire or control cells were detected by fluorescence-activated cell sorting. (B) The results are presented as the mean values of the percentages of positive cells \pm standard deviation. Each experiment was repeated at least three times, and each group was compared with the pEGFPC1 group. ${ }^{*} \mathrm{P}<0.05,{ }^{\# \#} \mathrm{P}<0.01$ vs. pEGFPC1. p, phosphorylated; -, extracellular signal-regulated kinase; p38, p38 mitogen-activated protein kinases.

cells co-cultured for $48 \mathrm{~h}$ with Aire cells $(\mathrm{P}<0.05$ and $\mathrm{P}<0.01$; Fig. 1). No significant differences were noted for the other master regulators, including Gata 3 in the Th2 cells, PU. 1 and IRF4 in the Th9 cells, AHR in the Th22 cells, or FoxP3 in the Tregs. These results indicate that Aire cells upregulate T-bet and ROR $\gamma \mathrm{T}$ transcription in $\mathrm{CD} 4^{+} \mathrm{T}$ cells.

In addition, the cytokines from different $\mathrm{CD} 4^{+} \mathrm{T}$ cell subsets were detected by FACS. FoxP3 was used to identify Tregs, as Tregs do not produce a typical cytokine (22). The data demonstrate that the percentages of IFN- $\gamma$ - and IL-17-expressing cells were higher than the control cells when the $\mathrm{CD} 4^{+} \mathrm{T}$ cells were co-cultured with Aire cells for $48 \mathrm{~h}$. The percentage of cells expressing FoxP3, IL-4, IL-9, and IL-22 did not significantly change; however, the percentage of IL-9-producing cells was increased when co-cultured with Aire cells (Fig. 2A and B). Other transcription factors may be required for Th9 differentiation, as no differences in the mRNA levels of the transcription factors, PU.1 or IRF4, were observed between the Aire and control cells. These results suggest that Aire has a positive role in inducing Th1 and Th17 development.

Aire-overexpressing DC2.4 cells induce Th1 and Th17 by upregulating $I L-12, I L-6$, and TGF- $\beta$ expression. DCs induce the expression of master regulators in $\mathrm{CD} 4^{+} \mathrm{T}$ cells by secreting cytokines, resulting in the further differentiation of $\mathrm{CD} 4^{+}$ $\mathrm{T}$ cell subsets from naïve $\mathrm{CD} 4^{+} \mathrm{T}$ cells. The expression of T-bet and $\mathrm{ROR} \gamma \mathrm{T}$ in $\mathrm{CD} 4^{+} \mathrm{T}$ cells is regulated by IL-12, and IL-6 and TGF- $\beta$, respectively, from DCs (23). Therefore, to investigate the mechanism underlying the Aire cells induction of Th1 and Th17 development, the mRNA and protein expression levels of IL-12, IL- 6 and TGF- $\beta$ in Aire cells were detected by RT-qPCR and ELISA. As presented in Fig. 3A and B, IL-12, IL- 6 , and TGF- $\beta$ mRNA expression levels were higher in the Aire cells than in the control cells. In addition, a similar trend in the protein levels of IL-12, IL- 6 and TGF- $\beta$ in the supernatants of the cultured cells was demonstrated by the Aire and control cells. These data suggest that Aire may affect the Th1 and Th17 subsets by regulating the secretion of cytokines by DCs.

To further determine whether the cytokines from Aire cells are involved in upregulating the Th1 and Th17 subsets, antibodies against IL-12, IL-6 and TGF- $\beta$ were used to block the cytokines in the supernatants of Aire and control cells prior to co-culture with $\mathrm{CD} 4^{+} \mathrm{T}$ cells. The expression levels of these cytokines in $\mathrm{CD} 4^{+} \mathrm{T}$ cells expressing IFN- $\gamma$ and IL-17A were evaluated by FACS following $48 \mathrm{~h}$ of co-culture (Fig. 4). No differences in the expression levels of these cytokines were observed for IFN- $\gamma$-expressing $\mathrm{CD}^{+} \mathrm{T}$ cells between Aire and control cells when IL-12 was blocked (Fig. 4A and C). In addition, no differences were observed for IL-17A-expressing $\mathrm{CD} 4{ }^{+} \mathrm{T}$ cells following blocking with anti-IL- 6 or anti-TGF- $\beta$ antibodies, or a combination of the two (Fig. 4B and C). These data demonstrate that Aire cells induce Th1 and Th17 differentiation by enhancing IL-12, IL- 6 and TGF- $\beta$ secretion.

Aire upregulates the expression levels of IL-12,IL-6 and TGF- $\beta$ via mitogen-activated protein kinase (MAPK) signaling. To investigate the signal transduction pathway by which Aire affects IL-12, IL-6, and TGF- $\beta$ expression in DCs, the activities of ERK and p38, which belong to the family of MAPKs associated with the production of these cytokines, were detected by FACS $(24,25)$. The results demonstrate that the phosphorylation levels of ERK and p38 were significantly increased in Aire cells $(\mathrm{P}<0.05$ and $\mathrm{P}<0.01$; Fig. 5A and $\mathrm{B})$. These data provide an explanation for the upregulation of IL-12, IL- 6 and TGF- $\beta$ by Aire in DCs.

\section{Discussion}

Aire was first identified in humans as the defective gene in the monogenic and autosomal recessive disorder, APS-I (26). The functions of Aire in the central immune organs, particularly in the thymus, have been extensively investigated and well defined. Previous studies have demonstrated that Aire promotes the ectopic expression of peripheral tissue-specific antigens (PTAs) in mTECs. This imposes central tolerance via the negative selection of self-reactive $T$ cells and the induction of Treg cells, which mediate peripheral immune tolerance $(2,3)$. The functions of Aire in peripheral tissues remain poorly understood and the subject of debate. Extrathymic Aire cells (eTACs), which are located in secondary lymphoid tissue, have been extensively investigated (27). Gardner et al (28) demonstrated that eTACs, as opposed to mTECs, functionally 
inactivate $\mathrm{CD} 4^{+} \mathrm{T}$ cells via the expression of a distinct and diverse array of self-antigens to induce peripheral tolerance, providing the first evidence of the action of Aire in peripheral tissue stromal cells. However, to the best of our knowledge, the function of Aire in peripheral hematopoietic cells remains undefined.

APECED presents with autoimmune polyendocrinopathy and chronic mucocutaneous candidiasis (CMC) (7), which usually results from an autoimmune response and $\mathrm{T}$ cell immunodeficiencies. Aire-expressing DCs may directly affect $\mathrm{CD}^{+}{ }^{+} \mathrm{T}$ cell subsets by expressing co-stimulatory molecules and by secreting cytokines. The endocrine disorders in APECED are clearly the result of autoimmunity (8), while the reason for the presence of $\mathrm{CMC}$ remains unclear. Previous studies have explained $\mathrm{CMC}$ as aberrant adaptive immunity, including a bias of the $\mathrm{T}$ cell repertoire resulting from the inappropriate role of AIRE as a transcriptional mediator (29). Furthermore, in the present study, Aire appeared to have little effect on costimulatory molecules in DC2.4 cells (data not shown). Therefore, the current study investigated whether Aire-overexpressing DCs affect $\mathrm{CD}^{+}{ }^{+} \mathrm{T}$ cell subsets by releasing paracrine cytokines. It was observed that Aire cells upregulate the mRNA levels of T-bet and ROR $\gamma \mathrm{T}$, and the protein levels of IFN- $\gamma$ and IL-17A in $\mathrm{CD}^{+} \mathrm{T}$ cells. This suggests that Aire cells induce Th1 and Th17 subset differentiation. Previous studies have identified that congenital errors in IFN- $\gamma$ cause endemic mycoses and that inborn errors in IL-17 are associated with CMC $(30,31)$. Furthermore, the Th1 and Th17 lineages are necessary for pathogen protection and clearance in various models, including C. albicans (32). Therefore, the current study hypothesized that decreased Th1 and Th17 differentiation, IFN- $\gamma$ and IL-17 generation caused by Aire-KO DCs, and the presence of autoantibodies targeting key antifungal cytokines may be one mechanism underlying APECED patient susceptibility to the Candida infection (33). Previously, Th1 cells were regarded as the cells that cause the onset and progression of autoimmune disorders, such as type 1 diabetes (T1D), by producing IFN- $\gamma$ (34). However, in-depth studies have indicated that the Th17 phenotype may be important in autoimmune disorders $(35,36)$. No differences in IFN- $\gamma$ or IL-17 expression levels were detected in the blood of APECED patients when compared with healthy control subjects, suggesting that IFN- $\gamma$ and IL-17 are not major reasons for autoimmunity in APECED patients (33). Conversely, Th17 cells delayed T1D in non-obese diabetic (NOD) mice treated with mycobacterial adjuvant (37), and IFN- $\gamma$ induction restored normoglycemia in NOD mice (38). Therefore, Aire expression in peripheral DCs may have a role in the prevention of Candida infection and autoimmune diseases by promoting Th1 and Th17 differentiation.

The current study demonstrated that Aire cells promote the differentiation of Th1 and Th17 cells by upregulating cytokine secretion. IL-12 is generally considered a potent inducer of Th1 cells (16), and Th17 cells are induced by the activities of various cytokines, including TGF- $\beta$ and IL-6 (21). Results of the present study are consistent with these reports; the mRNA and protein levels of TGF- $\beta$, IL-6, and IL-12 are increased in Aire-overexpressing DCs. Further analysis indicated that the neutralization of IL-12 in the co-culture system abrogated the differential Th1 subsets between the Aire and control cells, indicating the importance of IL-12 in the Th1 differentiation induced by Aire-overexpressing DCs. In addition, TGF- $\beta$ and IL-6 neutralization decreased Th17 induction, suggesting that TGF- $\beta$ and IL- 6 are critical in Th17 differentiation induced by Aire-overexpressing DCs. IL-12 produced by DCs transactivates T-bet and induces the differentiation of Th1 cells, which produce high levels of IFN- $\gamma$. Similarly, the transcription factor, ROR $\gamma$ t, which is required for Th17 differentiation and for IL-17A secretion, is regulated by TGF- $\beta$ and IL-6 from DCs (23). These findings indicate that Aire regulates the secretion of cytokines in DCs to affect $\mathrm{CD} 4^{+} \mathrm{T}$ cell subgroup differentiation, and regulate the immune response and tolerance.

The signaling pathway associated with IL-12, IL-6 and TGF- $\beta$ expression in Aire-transfected DCs was investigated to observe how Aire regulates cytokine secretion in DCs. p38 in DCs has been demonstrated to promote IL- 6 and TGF- $\beta$ production, and to mediate Th17 generation (39). The increased phosphorylation levels of $\mathrm{p} 38$ in the present study may explain the upregulation of IL- 6 and TGF- $\beta$ mediating Th17 differentiation. Furthermore, ERK activation may promote Th17 generation by increasing IL-6 expression and suppressing Tregs (40), which is consistent with the enhanced ERK activation in Aire cells. The polarization of Th1 cells may account for the increased phosphorylation of ERK and p38 in DCs following Aire transfection, as IL-12 secretion is increased via the activation of $\mathrm{p} 38$ and ERK (24). Additional mechanisms may contribute to this effect; for example, Aire may upregulate IL-12, IL- 6 and TGF- $\beta$ expression in DCs by activating ERK and $\mathrm{p} 38$.

In conclusion, data from the present study demonstrates that Aire cells induce Th1 and Th17 differentiation by upregulating cytokines in paracrine cells. This finding may explain why the genetic mutation of Aire simultaneously results in a self-tolerance disorder and in susceptibility to $C$. albicans infections.

\section{Acknowledgements}

The present study was supported by the National Natural Science Foundation of China (grant no. 81373127). The authors would like to thank Dr Xiumei Chi at the Translational Medical Research Institute of the First Hospital of Jilin University for assistance with flow cytometry.

\section{References}

1. Suzuki E, Kobayashi Y, Kawano O, Endo K, Haneda H, Yukiue H, Sasaki H, Yano M, Maeda M and Fujii Y: Expression of AIRE in thymocytes and peripheral lymphocytes. Autoimmunity 41: 133-139, 2008 .

2. Liston A, Lesage S, Wilson J, Peltonen L and Goodnow CC: Aire regulates negative selection of organ-specific T cells. Nat Immunol 4: 350-354, 2003.

3. Anderson MS, Venanzi ES, Klein L, Chen Z, Berzins SP, Turley SJ, von Boehmer H, Bronson R, Dierich A, Benoist C and Mathis D: Projection of an immunological self shadow within the thymus by the aire protein. Science 298: 1395-1401, 2002.

4. Abramson J, Giraud M, Benoist C and Mathis D: Aire's partners in the molecular control of immunological tolerance. Cell 140: 123-135, 2010.

5. Koh AS, Kuo AJ, Park SY, Cheung P, Abramson J, Bua D, Carney D, Shoelson SE, Gozani O, Kingston RE, et al: Aire employs a histone-binding module to mediate immunological tolerance, linking chromatin regulation with organ-specific autoimmunity. Proc Natl Acad Sci USA 105:15878-15883, 2008. 
6. Cavadini P, Vermi W, Facchetti F, Fontana S, Nagafuchi S, Mazzolari E, Sediva A, Marrella V, Villa A, Fishcer A, et al: AIRE deficiency in thymus of 2 patients with Omenn syndrome. J Clin Invest 115: 728-732, 2005.

7. Ahonen P, Myllärniemi S and Sipilä J and Perheentupa J: Clinical variation of autoimmune polyendocrinopathy-candidiasis-ectodermal dystrophy (APECED) in a series of 68 patients. N Engl J Med 322: 1829-1836,1990.

8. Perheentupa J: Autoimmune polyendocrinopathy-candidiasis-ectodermal dystrophy (APECED). Horm Metab Res 28 : 353-356,1996.

9. Pöntynen N, Strengell M, Sillanpää N, Saharinen J, Ulmanen I, Julkunen I and Peltonen L: Critical immunological pathways are downregulated in APECED patient dendritic cells. J Mol Med Berl 86: 1139-1152, 2008.

10. Cohen JN, Guidi CJ, Tewalt EF, Qiao H, Rouhani SJ, Ruddell A, Farr AG, Tung KS and Engelhard VH: Lymph node-resident lymphatic endothelial cells mediate peripheral tolerance via Aire-independent direct antigen presentation. J Exp Med 207: 681-688, 2010.

11. Fletcher AL, Lukacs-Kornek V, Reynoso ED, Pinner SE, Bellemare-Pelletier A, Curry MS, Collier AR, Boyd RL and Turley SJ: Lymph node fibroblastic reticular cells directly present peripheral tissue antigen under steady-state and inflammatory conditions. J Exp Med 207: 689-697, 2010.

12. Lee JW, Epardaud M, Sun J, Becker JE, Cheng AC, Yonekura AR, Heath JK, Turley SJ: Peripheral antigen display by lymph node stroma promotes $\mathrm{T}$ cell tolerance to intestinal self. Nat Immunol 8: 181-190, 2007.

13. Ramsey C, Hässler S, Marits $P$, Kämpe $O$, Surh CD, Peltonen L and Winqvist $\mathrm{O}$ : Increased antigen presenting cell-mediated $\mathrm{T}$ cell activation in mice and patients without the autoimmune regulator. Eur J Immunol 36: 305-317, 2006.

14. Asano M, Toda M, Sakaguchi N and Sakaguchi S: Autoimmune disease as a consequence of developmental abnormality of a T cell subpopulation. J Exp Med 184:387-396, 1996.

15. Espinosa V and Rivera A: Cytokines and the regulation of fungus-specific $\mathrm{CD}^{+} \mathrm{T}$ cell differentiation. Cytokine 58 : 100-106, 2012.

16. Guo L, Wei G, Zhu J, Liao W, Leonard WJ, Zhao K and Paul W: IL-1 family members and STAT activators induce cytokine production by Th2, Th17, and Th1 cells. Proc Natl Acad Sci USA 106: 13463-13468, 2009.

17. Kagami S, Rizzo HL, Lee JJ, Koguchi Y and Blauvelt A Circulating Th17, Th22, and Th1 cells are increased in psoriasis. J Invest Dermatol 130: 1373-1383, 2010.

18. Kerzerho J, Maazi H, Speak AO, Szely N, Lombardi V, Khoo B, Geryak S, Lam J, Soroosh P, Van Snick J and Akbari O: Programmed cell death ligand2 regulates TH9 differentiation and induction of chronic airway hyperreactivity. J Allergy Clin Immunol 131: 1048-1057, 1057.e1-1057.e2, 2013.

19. Sakaguchi S, Sakaguchi N, Asano M, Itoh M and Toda M: Immunologic self-tolerance maintained by activated $\mathrm{T}$ cells expressing IL-2 receptor alpha-chains (CD25) Breakdown of a single mechanism of self-tolerance causes various autoimmune diseases. J Immunol 155: 1151-1164, 1995.

20. Zhu W, Yang W, He Z, Liao X, Wu J, Sun J, Yang Y and Li Y: Overexpressing autoimmune regulator regulates the expression of toll-like receptors by interacting with their promoters in RAW264.7 cells. Cell Immunol 270: 156-163, 2011.

21. Egawa T, Tillman RE, Naoe Y, Taniuchi I and Littman DR: The role of the Runx transcription factors in thymocyte differentiation and in homeostasis of naive T cells. J Exp Med 204: 1945-1957, 2007

22. Miyara M, Yoshioka Y, Kitoh A, Shima T, Wing K, Niwa A, Parizot C, Taflin C, Heike T, Valeyre D, et al: Functional delineation and differentiation dynamics of human $\mathrm{CD} 4^{+} \mathrm{T}$ cells expressing the FoxP3 transcription factor. Immunity 30: 899-911, 2009.
23. Zhu J, Yamane $\mathrm{H}$ and Paul WE: Differentiation of effector CD4 ${ }^{+}$ T cell populations (*). Annu Rev Immunol 28: 445-89, 2010.

24. Huang G, Wang Y and Chi H: Control of T cell fates and immune tolerance by p38 $\alpha$ signaling in mucosal CD103+ dendritic cells. J Immunol 191: 650-659, 2013.

25. Dong Q, Sugiura T, Toyohira Y, Yoshida Y, Yanagihara N and Karasaki Y: Stimulation of IFN- $\gamma$ production by garlic lectin in mouse spleen cells: Involvement of IL-12 via activation of p38 MAPK and ERK in macrophages. Phytomedicine 18: 309-16, 2011.

26. Nagamine K, Peterson P, Scott HS, Kudoh J, Minoshima S, Heino M, Krohn KJ, Lalioti MD, Mullis PE, Antonarakis SE, et al: Positional cloning of the APECED gene. Nat Genet 17: 393-398, 1997.

27. Zhang $R$ and Turka LA: A breath of fresh aire. Immunity 39: 427-429, 2013.

28. Gardner JM, Devoss JJ, Friedman RS, Wong DJ, Tan YX, Zhou X, Johannes KP, Su MA, Chang HY, Krummel MF, et al: Deletional tolerance mediated by extrathymic Aire-expressing cells. Science 321: 843-847, 2008.

29. Kekäläinen E, Tuovinen H, Joensuu J, Gylling M, Franssila R, Pöntynen N, Talvensaari K, Perheentupa J, Miettinen A and Arstila TP: A defect of regulatory T cells in patients with autoimmune polyendocrinopathy-candidiasis-ectodermal dystrophy. J Immunol 178: 1208-1215, 2007.

30. Lanternier F, Cypowyj S, Picard C, Bustamante J, Lortholary O, Casanova JL and Puel A: Primary immunodeficiencies underlying fungal infections. Curr Opin Pediatr 25: 736-747, 2013.

31. Ling Y and Puel A: IL-17 and infections. Actas Dermosifiliogr 105 Suppl 1: 34-40, 2014

32. Murdock BJ, Teitz-Tennenbaum S, Chen GH, Dils AJ, Malachowski AN, Curtis JL, Olszewski MA and Osterholzer JJ: Early or late IL-10 blockade enhances Th1 and Th17 effector responses and promotes fungal clearance in mice with cryptococcal lung infection. J Immunol 193: 4107-4116, 2014.

33. Kisand K, Lilic D, Casanova JL, Peterson P, Meager A and Willcox N: Mucocutaneous candidiasis and autoimmunity against cytokines in APECED and thymoma patients: Clinical and pathogenetic implications. Eur J Immunol 41: 1517-1527, 2011 .

34. Mosmann TR, Cherwinski H, Bond MW, Giedlin MA and Coffman RL: Two types of murine helper T cell clone. I. Definition according to profiles of lymphokine activities and secreted proteins. J Immunol 136: 2348-2357,1986.

35. Emamaullee JA, Davis J, Merani S, Toso C, Elliott JF, Thiesen A and Shapiro M: Inhibition of Th17 cells regulates autoimmune diabetes in NOD mice. Diabetes 58: 1302-1311, 2009.

36. Dolff S, Quandt D, Feldkamp T, Jun C, Mitchell A, Hua F, Specker C, Kribben A, Witzke $\mathrm{O}$ and Wilde B: Increased percentages of PD-1 on CD4+ T cells is associated with higher INF- $\gamma$ production and altered IL-17 production in patients with systemic lupus erythematosus. Scand J Rheumatol 43: 307-313, 2014.

37. NikoopourE, Schwartz JA, Huszarik K, Sandrock C, Kroughly O, Lee-Chan E and Singh B: Th17 polarized cells from nonobese diabetic mice following mycobacterial adjuvant immunotherapy delay type 1 diabetes. J Immunol 184: 4779-4788, 2010.

38. Jain R, Tartar DM, Gregg RK, Divekar RD, Bell JJ, Lee HH, Yu P, Ellis JS, Hoeman CM, Franklin CL and Zaghouani H: Innocuous IFNgamma induced by adjuvant-free antigen restores normoglycemia in NOD mice through inhibition of IL-17 production. J Exp Med 205: 207-218, 2008.

39. Gonghua H, Yanyan W, Peter V, Thirumala-Devi K, Kinya O and Hongbo C: p38 a signaling programs dendritic cells to drive TH17 cell differentiation and autoimmune inflammation. Nat Immunol 13: 152-161, 2013

40. Liu H, Yao S, Dann SM, Qin H, Elson CO and Cong Y: ERK differentially regulates Th17- and Treg-cell development and contributes to the pathogenesis of colitis. Eur J Immunol 43 1716-1726, 2013 